\title{
Renin inhibition reduces hypercholesterolemia-induced atherosclerosis in mice
}

\author{
Hong Lu,, ${ }^{1}$ Debra L. Rateri, ${ }^{1}$ David L. Feldman, ${ }^{2}$ Richard J. Charnigo Jr., ${ }^{3}$ Akiyoshi Fukamizu,, \\ Junji Ishida, ${ }^{4}$ Elizabeth G. Oesterling, ${ }^{5}$ Lisa A. Cassis, ${ }^{1,6}$ and Alan Daugherty ${ }^{1,6}$ \\ ${ }^{1}$ Cardiovascular Research Center, University of Kentucky, Lexington, Kentucky, USA. ${ }^{2}$ Novartis Institutes for Biomedical Research, \\ East Hanover, New Jersey, USA. ${ }^{3}$ Department of Statistics, University of Kentucky, Lexington, Kentucky, USA. \\ ${ }^{4}$ Center for Tsukuba Advanced Research Alliance, Aspect of Functional Genomic Biology, University of Tsukuba, Tsukuba, Japan. \\ ${ }^{5}$ Graduate Center for Toxicology and ${ }^{6}$ Graduate Center for Nutritional Sciences, University of Kentucky, Lexington, Kentucky, USA.
}

\begin{abstract}
The role of the renin angiotensin system (RAS) in atherosclerosis is complex because of the involvement of multiple peptides and receptors. Renin is the rate-limiting enzyme in the production of all angiotensin peptides. To determine the effects of renin inhibition on atherosclerosis, we administered the novel renin inhibitor aliskiren over a broad dose range to fat-fed LDL receptor-deficient $\left(\mathrm{Ldll}^{-/}\right)$mice. Renin inhibition resulted in striking reductions of atherosclerotic lesion size in both the aortic arch and the root. Subsequent studies demonstrated that cultured macrophages expressed all components of the RAS. To determine the role of macrophage-derived angiotensin in the development of atherosclerosis, we transplanted renin-deficient bone marrow to irradiated $\mathrm{Ldlr}^{-/-}$mice and observed a profound decrease in the size of atherosclerotic lesions. In similar experiments, transplantation of bone marrow deficient for angiotensin II type 1a receptors failed to influence lesion development. We conclude that renin-dependent angiotensin production in macrophages does not act in an autocrine/paracrine manner. Furthermore, in vitro studies demonstrated that coculture with renin-expressing macrophages augmented monocyte adhesion to endothelial cells. Therefore, although previous work suggests that angiotensin peptides have conflicting effects on atherogenesis, we found that renin inhibition profoundly decreased lesion development in mice.
\end{abstract}

\section{Introduction}

There is evolving complexity in the renin angiotensin system (RAS) because of the identification of a spectrum of bioactive angiotensin peptides including AngII, AngIII, AngIV, and Ang1-7 (1-3). There is also an increasing number of receptors that have been recognized to interact with these angiotensin peptides including AngII type 1 (AT1) receptors, AT2 receptors, AT4 receptors, and mas receptors $(4,5)$.

AngII has long been considered the major bioactive effector molecule of the RAS and has been recognized as a major contributor to hypercholesterolemia-induced atherosclerosis $(6,7)$. Chronic infusion of AngII augments the size of atherosclerotic lesions in LDL receptor-deficient ( $\mathrm{Ldlr}^{-/}$) and apoE-/- mice (8-11). Conversely, pharmacological antagonists of specific components of the RAS have decreased the extent of atherosclerosis. Many studies have demonstrated that angiotensin-converting enzyme (ACE) inhibitors and AT1 receptor antagonists reduce atherosclerotic lesion size $(7,12-15)$. However, a mechanistic basis for the beneficial effects observed with ACE inhibitors and AT1 receptor antagonists has not been defined. It is currently unclear whether the efficacy is due to inhibition of AngII production, the effect of AngII on AT2 receptors, or the continued presence of other bioactive angioten-

Nonstandard abbreviations used: ACE, angiotensin-converting enzyme; AT1 receptor, AngII type 1 receptor; HPF, high-power field; LDLR, LDL receptor; RAS, renin angiotensin system.

Conflict of interest: Alan Daugherty and Lisa A. Cassis received research support from Novartis Institutes for Biomedical Research. David L. Feldman is an employee of Novartis Institutes for Biomedical Research.

Citation for this article: J. Clin. Invest. 118:984-993 (2008). doi:10.1172/JCI32970. sin peptides that interact with receptors other than AT1 receptors. Renin is not only the rate-limiting enzyme in AngII formation, but also shows remarkable substrate specificity for angiotensinogen, making it an attractive target for therapeutic inhibition of all angiotensin peptides. Thus, renin inhibition may provide a unique approach to define the role of angiotensin peptides in the development of atherosclerosis.

In addition to the systemic RAS, it has now been recognized that several tissues express components of the RAS and possess the ability to synthesize AngII (16-20). With regard to atherosclerosis, all components of the classical RAS pathway have been identified in lesions and are associated predominantly with macrophages (6, 21-23). The presence of mRNA and protein for RAS components has also been detected in cultured macrophages (24-26). Although there are several potential sources of angiotensin peptides, the relative contribution to lesion formation of systemic versus local sources has not been defined.

Recent studies have demonstrated that AT1a receptors have a profound effect on atherosclerosis generated by hypercholesterolemia alone $(6,7)$ or in combination with AngII infusion (11). Angiotensin peptides, particularly AngII, have well-defined effects on several cell types present in atherosclerosis. These effects are particularly prominent for smooth muscle cells and endothelium, with less prominent effects on macrophages $(11,27,28)$. To date, the contribution of AT1a receptors on specific cell types to the atherogenic process has not been determined unequivocally.

The purpose of the current study was to determine whether whole-body inhibition of renin decreases atherosclerotic lesion size. Furthermore, we determined whether macrophage expression of 
Table 1

Effects of renin inhibition in Ldlr-1- mice fed a fat-supplemented diet for 12 weeks

\begin{tabular}{lcccc} 
& Vehicle & $\begin{array}{c}\text { Aliskiren } \\
(\mathbf{2 . 5} \mathbf{~ m g / k g / d )}\end{array}$ & $\begin{array}{c}\text { Aliskiren } \\
\mathbf{( 2 5} \mathbf{~ m g / k g / d )}\end{array}$ & $\begin{array}{c}\text { Aliskiren } \\
(\mathbf{5 0} \mathbf{~ m g} / \mathbf{k g} / \mathbf{d})\end{array}$ \\
$n$ & & 14 & 16 & 6 \\
Body wt $(\mathrm{g})$ & 15 & $28.9 \pm 1.4$ & $29.3 \pm 0.7$ & $29.9 \pm 0.7$ \\
Plasma cholesterol $(\mathrm{mg} / \mathrm{dl})$ & $32.3 \pm 1.3$ & $1,288 \pm 109$ & $1,225 \pm 129$ & $1,201 \pm 102$ \\
Plasma aliskiren $(\mu \mathrm{M})$ & $1,185 \pm 93$ & $0.03 \pm 0.005^{\mathrm{A}}$ & $0.71 \pm 0.23^{\mathrm{A}, \mathrm{B}}$ & $0.73 \pm 0.09^{\mathrm{A}, \mathrm{B}}$ \\
Plasma renin $(\mathrm{ng} / \mathrm{ml} / 30 \mathrm{~min})$ & 0 & $31.7 \pm 4.5^{\mathrm{A}}$ & $31.9 \pm 2.9^{A}$ & $33.0 \pm 2.9^{A}$ \\
Plasma aldosterone $(\mathrm{pg} / \mathrm{ml})$ & $13.8 \pm 2.7$ & $330 \pm 55$ & $229 \pm 24$ & $\mathrm{ND}$ \\
\hline
\end{tabular}

Values are mean \pm SEM. ND, not determined. ${ }^{A} P<0.0001$ versus vehicle. ${ }^{\mathrm{B}} P<0.0001$ versus $2.5 \mathrm{mg} / \mathrm{kg} / \mathrm{d}$ aliskiren

renin contributed to the development of atherosclerosis by generating chimeric mice with renin deficiency in bone marrow-derived cells. Finally, we also defined autocrine/paracrine effects of locally synthesized angiotensin peptides on AT1a receptors in the development of atherosclerosis.

\section{Results}

Systemic renin inhibition strikingly reduced atherosclerosis. Aliskiren, an octanamide, is the first representative of a new class of nonpeptide, low-molecular weight renin inhibitors. Its action decreases plasma concentrations of AngII, which causes depression of negative feedback of renin secretion from the kidney and results in increased plasma renin concentrations (29-31). In this study, aliskiren was administered at 3 different doses to produce increasing systemic inhibition of renin. Aliskiren produced no changes in body weight, plasma cholesterol concentrations, plasma aldosterone concentrations (Table 1), or lipoprotein-cholesterol distribution (data not shown) in $\mathrm{Ldlr}^{-/-}$mice. The lowest dose of aliskiren, $2.5 \mathrm{mg} / \mathrm{kg} / \mathrm{d}$, gave plasma concentrations that were 5 -fold higher than the $\mathrm{IC}_{50}$ against mouse renin $(6.22 \pm 2.25 \mathrm{nM})$, while the higher doses of 25 and $50 \mathrm{mg} / \mathrm{kg} / \mathrm{d}$ gave similar plasma concentrations that were 100 -fold above the $\mathrm{IC}_{50}$ (Table 1). All doses of aliskiren increased plasma renin concentrations. Renal renin mRNA increased in a dose-dependent manner $(P<0.0001$; Figure 1$)$. Conversely, mRNA abundances of angiotensinogen, ACE, ACE2, AT1a receptors, and AT2 receptors did not change in renal tissue (Supplemental Figure 1; supplemental material available online with this article; doi:10.1172/JCI32970DS1). Renin inhibition was further demonstrated by the decreased plasma concentrations of angiotensin peptides (Figure 2). Infusion of $2.5 \mathrm{mg} / \mathrm{kg} / \mathrm{d}$ aliskiren, the lowest dose tested, reduced plasma AngII and the sum of angiotensin peptide concentrations, while the infusion of $25 \mathrm{mg} / \mathrm{kg} / \mathrm{d}$ led to near ablation of all peptides in plasma (Figure 2).

There was a sustained decrease in systolic blood pressure during aliskiren infusion at 25 and $50 \mathrm{mg} / \mathrm{kg} / \mathrm{d}(P<0.0001$; Figure 3$)$. The administration of $2.5 \mathrm{mg} / \mathrm{kg} / \mathrm{d}$ aliskiren did not produce an overall statistically significant sustained reduction in systolic blood

Figure 1 pressure, although there was a decrease at 1 interval measured. Because we have previously demonstrated that hypercholesterolemia caused a mild increase in blood pressure associated with activation of the RAS (6), we also sought to determine the effect of the $50-\mathrm{mg} / \mathrm{kg} / \mathrm{d}$ aliskiren dose on systolic blood pressure in wild-type C57BL/ 6 male mice fed normal laboratory diet. The basal systolic blood pressure in these normolipidemic mice was less than that in strain-, age-, and gender-matched fat-fed Ldlr-/- mice. Administration of the highest dose of aliskiren did not change systolic blood pressures in normolipidemic C57BL/ 6 mice, whereas both the $25-$ and $50-\mathrm{mg} / \mathrm{kg} / \mathrm{d}$ doses reduced systolic blood pressures in hypercholesterolemic $\mathrm{Ldlr}^{-/}$mice to the level observed in normolipidemic C57BL/6 mice (Figure 3).

Atherosclerotic lesion size was measured in both the aortic intima by the en face technique and in sections of aortic root. Reductions in atherosclerosis were profound in both regions, with significant reductions in atherosclerotic lesion size observed in mice administered the $2.5-\mathrm{mg} / \mathrm{kg} / \mathrm{d}$ dose of aliskiren. The 25 - and $50-\mathrm{mg} / \mathrm{kg} / \mathrm{d}$ doses produced similar results, with near ablation of
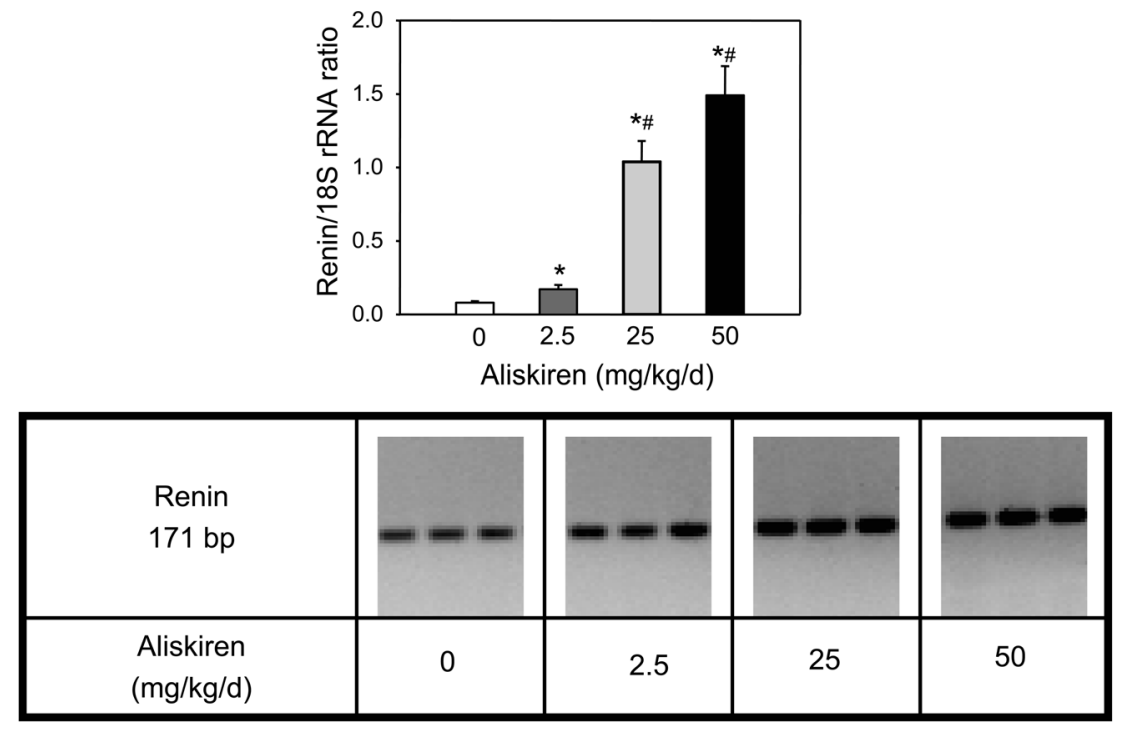

Renin inhibition dose-dependently increased renal renin mRNA abundance. Renin mRNA abundance (renin/18S rRNA ratio) was quantified by real-time PCR ( $n=5$ per group). mRNA bands by gel electrophoresis are also shown; the lanes were run on the same gel but were noncontiguous. Data are mean \pm SEM. ${ }^{*} P<0.0001$ versus vehicle; ${ }^{\#} P<0.0001$ versus $2.5 \mathrm{mg} / \mathrm{kg} / \mathrm{d}$ aliskiren. 


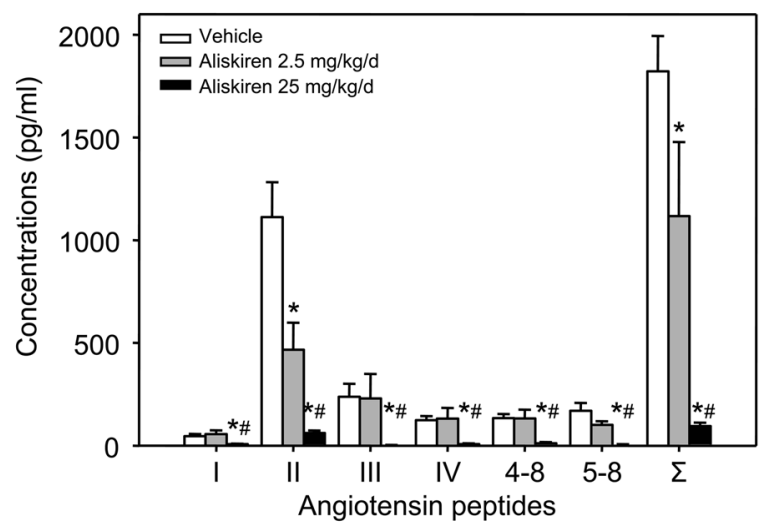

Figure 2

Renin inhibition dose-dependently decreased angiotensin peptide concentrations in mouse plasma. Angiotensin peptides in mouse plasma were resolved by HPLC and quantified with radioimmunoassay $(n=4$ per group). Data are mean \pm SEM. ${ }^{*} P<0.05$ versus vehicle; $\# P<0.05$ versus $2.5 \mathrm{mg} / \mathrm{kg} / \mathrm{d}$ aliskiren.

lesion formation in the aortic arch (Figure 4A). The administration of aliskiren also profoundly reduced atherosclerotic lesion size throughout the aortic root (vehicle, $0.16 \pm 0.02 \mathrm{~mm}^{2} ; 2.5 \mathrm{mg} / \mathrm{kg} / \mathrm{d}$, $0.09 \pm 0.01 \mathrm{~mm}^{2} ; 25 \mathrm{mg} / \mathrm{kg} / \mathrm{d}, 0.07 \pm 0.01 \mathrm{~mm}^{2} ; 50 \mathrm{mg} / \mathrm{kg} / \mathrm{d}$, $0.05 \pm 0.01 \mathrm{~mm}^{2} ; P<0.0001 ;$ Figure 4B). All doses of aliskiren produced similar reductions in lesion size in this region.

Increased blood pressure is a consistent risk factor for the development of atherosclerotic diseases in humans (32). Thus, we investigated the association between systolic blood pressure and atherosclerotic lesion size in both aortic arch and root in mice administered different doses of aliskiren. First, we calculated Pearson correlations between systolic blood pressure and (logtransformed) atherosclerotic lesion size within each of the 4 study groups. There were no significant correlations between systolic blood pressure and atherosclerotic lesion size in either aortic arch or root (data not shown). We also used linear regression to express atherosclerotic lesion size in terms of study group assignment and systolic blood pressure (Supplemental Figure 2). Even with adjustment for differences in systolic blood pressure, all doses of aliskiren still significantly reduced atherosclerotic lesion size in both the aortic arch and $\operatorname{root}(P<0.001)$. On the other hand, systolic blood pressure did not predict atherosclerotic lesion size once we controlled for aliskiren dosage.

Immunostaining of atherosclerotic tissue in aortic roots was performed to determine whether reductions in lesion size during renin inhibition were accompanied by changes in cell composition. Immunostaining of lesions demonstrated that the predominance of macrophages in vehicle-infused mice was similar in aliskireninfused mice (Figure 4C).

Systemic renin inhibition did not affect specific oxidant mechanisms. AngII has previously been shown to promote macrophage expression of 12/15 lipoxygenase protein, which promotes atherosclerosis in $\mathrm{Ldlr}^{-/-}$mice $(33,34)$. The abundance of $12 / 15$ lipoxygenase protein was determined in mouse peritoneal macrophages by Western blotting. However, we were unable to demonstrate that aliskiren administration had any effect on macrophage 12/15 lipoxygenase expression (data not shown). We also measured serum titers of autoantibodies against malondialdehyde-LDL
(MDA-LDL), which has previously been used as an index of atherosclerosis-related oxidant mechanisms (35). However, serum titers of MDA-LDL autoantibodies were unchanged by aliskiren administration (data not shown).

Cultured macrophages expressed all components of RAS and synthesized the unique precursor angiotensinogen. To determine whether macrophages express all components of the classic pathway for angiotensin peptide production, RT-PCR was used with primers that have annealing sites across intronic boundaries for each pair (36). mRNA expression of angiotensinogen, renin, and ACE was detected in mouse macrophages (Supplemental Figure 3A).

The ability of macrophages to secrete angiotensinogen was investigated by Western blotting (Supplemental Figure 3B). Mouse plasma protein had 2 specific bands of angiotensinogen at 52 and 64 $\mathrm{kDa}$, whereas peritoneal macrophage culture medium presented a single band at $64 \mathrm{kDa}$ that was highly glycosylated, as reported previously (36). We have been unable to develop an antibody to detect the presence of secreted renin in a Western blotting format.

The deficiency of renin has the potential to upregulate other enzymes with similar properties, such as cathepsin D (17). However, renin deficiency had no effect on cathepsin D mRNA abundance in macrophages (Supplemental Figure 3C).

Renin deficiency in bone marrow-derived cells reduced atherosclerotic lesion size unrelated to their AT1 a receptors. Because whole-body inhibition of renin profoundly decreased atherosclerosis, and because isolated macrophages contain all the components for angiotensin peptide synthesis including renin, we examined the effect of renin originating from bone marrow-derived cells. We used the strategy of irradiating $\mathrm{Ldlr}^{-/-}$mice and repopulating with bone marrow-derived cells from renin $^{+/+}$or renin $/-$mice. Although bone marrow has the potential to differentiate into many cell types, this procedure predominantly repopulates macrophages in atherosclerotic lesions (37).

In $\mathrm{Ldlr}^{-/}$recipient mice, the renin genotype of bone marrowderived cells used to repopulate mice had no influence on body weight, wbc counts, plasma cholesterol concentrations, plasma concentrations of aldosterone and renin, or systolic blood pressure (Table 2). The chimeric nature of the mice was confirmed at the termination of the study by genotyping the bone marrow

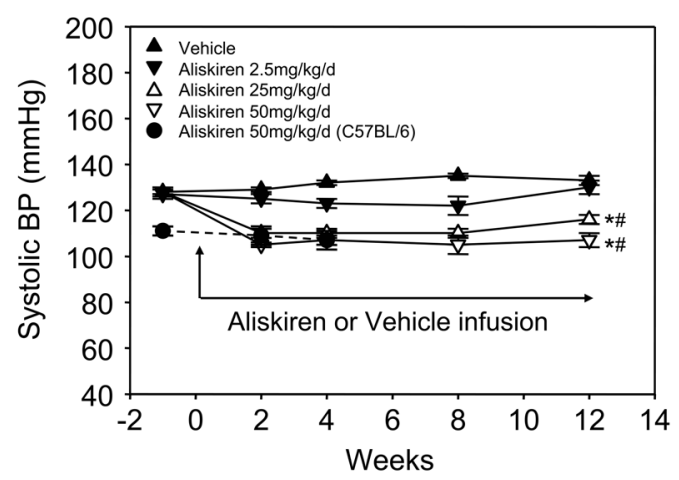

\section{Figure 3}

Renin inhibition decreased systolic blood pressure in Ldlr-1- mice. Systolic blood pressure was measured in $\mathrm{Ldlr}^{-/}$mice 1 week prior to pump implantation and during 2, 4, 8, and 12 weeks of drug administration at the indicated doses. Aliskiren was also administered at a dose of $50 \mathrm{mg} / \mathrm{kg} / \mathrm{d}$ to normal diet-fed Ldlr ${ }^{+/+}$C57BL/6 mice (dotted line). Points represent the mean of weekly observations; error bars denote SEM. ${ }^{*} P<0.0001$ versus vehicle; ${ }^{\#} P<0.0001$ versus $2.5 \mathrm{mg} / \mathrm{kg} / \mathrm{d}$ aliskiren. 
A

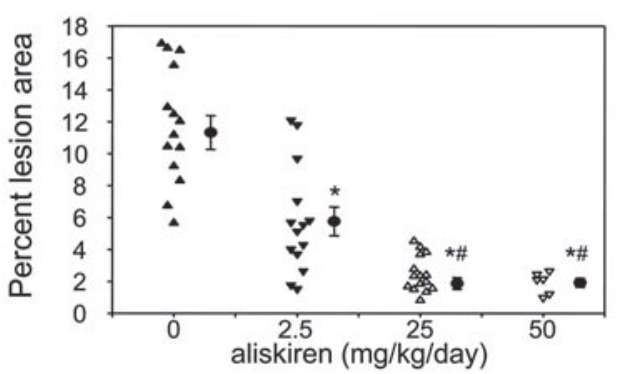

B
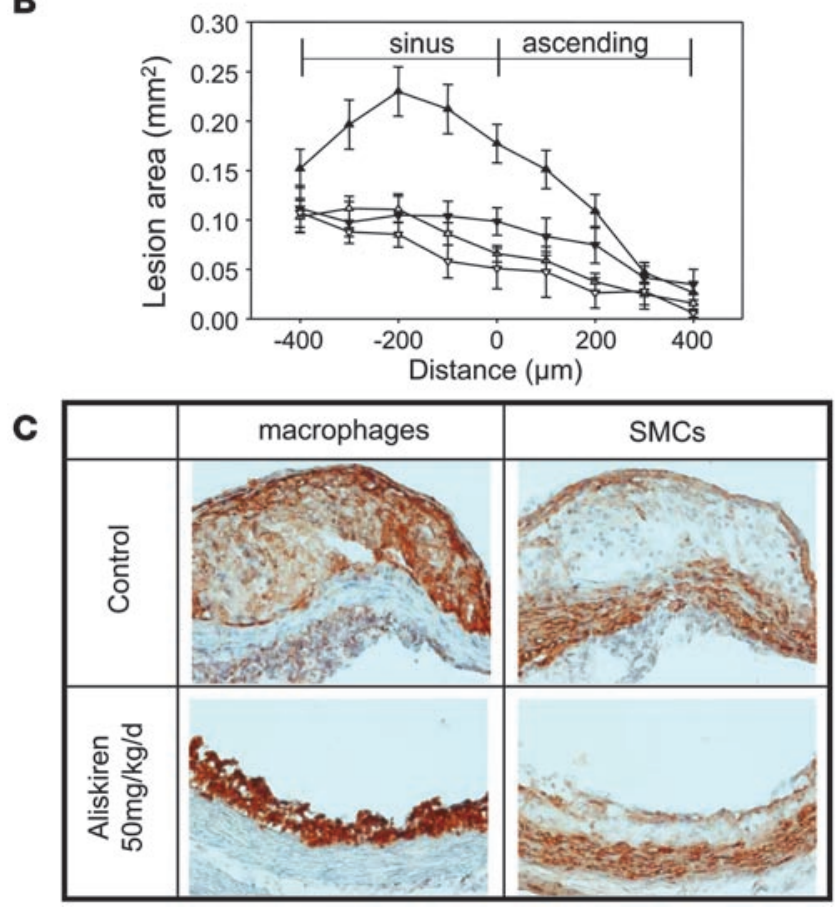

(Figure 5A). Despite the lack of systemic changes, mice repopulated with cells derived from renin ${ }^{-/}$mice had a large reduction in atherosclerotic lesion size (Figure 5B). Immunostaining of lesions demonstrated that both groups had predominantly macrophagerich lesions. Immunostaining for renin was more apparent in $\mathrm{Ldll}^{-/-}$mice repopulated with cells from $\mathrm{renin}^{+/+}$mice compared with cells from renin ${ }^{-/}$mice (Figure 5C).

To study a potential oxidant mechanism of macrophage renin on atherogenesis, we determined macrophage 12/15 lipoxygenase expression. As with the aliskiren studies, we were unable to detect an effect of renin deficiency on macrophage 12/15 lipoxygenase expression (data not shown). We also determined whether renin deficiency in macrophages altered lipid accumulation. Cultured peritoneal macrophages from renin ${ }^{+/}$or renin ${ }^{-/}$mice were incubated in serum-free DMEM in the presence of acetylated LDL $(20 \mu \mathrm{g} / \mathrm{ml})$ for 24 hours. Staining with Oil Red O showed intracellular accumulation of neutral lipid in both $\mathrm{renin}^{+/+}$and renin $^{-/}$macrophages incubated with acetylated LDL. To quantify the cholesterol content in macrophages incubated with acetylated LDL, we measured unesterified and esterified cholesterol by gas chromatography-mass spectrometric analysis (GC-MS). Renin deficiency in mouse macrophages did not result in any change in acetylated LDL-induced increases in intracellular unesterified and esterified cholesterol (Supplemental Figure 4).

\section{Figure 4}

Renin inhibition reduced atherosclerotic lesion development without overtly altering cellular composition. (A) Atherosclerotic lesion size was measured on the intimal surface of aortic arches. Triangles represent individual mice; circles represent the mean; error bars denote SEM. ${ }^{\star} P<0.0001$ versus vehicle; ${ }^{\#} P<0.01$ versus $2.5 \mathrm{mg} / \mathrm{kg} / \mathrm{d}$ aliskiren. (B) Atherosclerotic lesion size was measured in aortic roots. Data are represented throughout the aorta root, with transitions between the sinus and ascending arch depicted as 0 . Filled triangles, PBS vehicle $(n=14)$; filled inverted triangles, $2.5 \mathrm{mg} / \mathrm{kg} / \mathrm{d}$ aliskiren $(n=14)$; open triangles, $25 \mathrm{mg} / \mathrm{kg} / \mathrm{d}$ aliskiren $(n=15)$; open inverted triangles, $50 \mathrm{mg} / \mathrm{kg} / \mathrm{d}$ aliskiren $(n=6)$. Values are mean \pm SEM. (C) Examples of atherosclerotic lesions immunostained for macrophages and smooth muscle cells. Aortic roots were immunostained using rat anti-mouse CD68 (1:200, left), or a rabbit anti- $\alpha-S M A(1: 200$, right). Original magnification, $\times 200$.

We subsequently defined whether angiotensin peptides generated by macrophages act primarily in an autocrine/paracrine manner to promote lesion formation. Of the AT1 receptor subtypes, only AT1a receptor was detected in macrophages (Figure 6A). Therefore, we performed a bone marrow transplantation study in which we irradiated $\mathrm{Ldlr}^{-/-}$mice and repopulated them with bone marrow-derived cells from AT1a receptor ${ }^{+/+}$or AT1a receptor $^{-1}$ mice. The parameters described for the renin bone marrow transplantation studies were also unaffected by the AT1a receptor genotype of the bone marrow cells (Table 3). The genotype of the peritoneal macrophages at the end of the study confirmed the chimeric nature of the mice (Figure 6B). Furthermore, in contrast to the profound effects of renin deficiency, we failed to detect any significant effect of AT1a receptor genotype of bone marrow-derived cells on the size of atherosclerotic lesions (Figure 6C).

Macrophage renin deficiency reduced monocyte adhesion to endothelial cells. Because renin deficiency in bone marrow-derived cells decreased atherosclerosis unrelated to autocrine effects on macrophage AT1a receptors, we studied whether renin expression in macrophages would affect adhesion of monocytes to endothelial cells, a pivotal process in the initiation and progression of atherosclerosis. Thus, we examined THP-1 monocyte adhesion to HUVECs. Initial studies demonstrated that AngII $\left(10^{-7} \mathrm{M}\right.$ for 24 hours) promoted monocyte adhesion to endothelial cells (Figure 7A). AngII-induced monocyte adhesion to HUVECs was not associated with increased endothelial VCAM-1 expression. Although AngII failed to increase VCAM-1 expression, the ability of HUVECs to express this adhesion molecule was confirmed by incubation with TNF- $\alpha$ (Supplemental Figure 5). Antagonism of AngII-induced monocyte adhesion by $10^{-6} \mathrm{M}$ losartan demonstrated the role of AT1 receptors (Figure 7B). Having defined the role of AngII to promote adhesion, we coincubated confluent endothelial monolayers with peritoneal macrophages harvested from either renin ${ }^{+/+}$or renin ${ }^{-/-}$mice that were cultured in lower chambers of Transwell plates. Monocyte adhesion was significantly increased when HUVECs were coincubated with macrophages from $\mathrm{renin}^{+/+}$mice compared with coincubation with macrophages from renin ${ }^{-/}$mice (Figure 7C).

\section{Discussion}

Aliskiren effectively inbibits mouse renin and profoundly reduces atherosclerosis. The present study demonstrated that renin inhibition reduced the size of atherosclerotic lesions in a dose-dependent manner in $\mathrm{Ldll}^{-/-}$mice fed a fat-enriched diet. Renin inhibition was achieved by continuous subcutaneous infusion of the novel inhibitor aliskiren. Aliskiren is a potent inhibitor of human 


\section{Table 2}

Effects of renin deficiency in bone marrow-derived cells in LdIr-/- mice fed a fat-supplemented diet for 12 weeks

\begin{tabular}{lcc} 
& Renin $^{+/+}$ & Renin $^{-/-}$ \\
$n$ & 12 & 10 \\
Body wt $(\mathrm{g})$ & $32.5 \pm 0.7$ & $34.6 \pm 0.9$ \\
wbc count $\left(10^{3} / \mu \mathrm{l}\right)$ & $8.2 \pm 1.0$ & $7.5 \pm 0.6$ \\
Plasma cholesterol $(\mathrm{mg} / \mathrm{dl})$ & $1,294 \pm 46$ & $1,357 \pm 54$ \\
Plasma renin $(\mathrm{ng} / \mathrm{ml} / 30 \mathrm{~min})$ & $12.5 \pm 1.8$ & $12.0 \pm 1.8$ \\
Plasma aldosterone $(\mathrm{pg} / \mathrm{ml})$ & $274.3 \pm 67.5$ & $302.2 \pm 91.9$ \\
Systolic BP $(\mathrm{mmHg})$ & $139 \pm 4$ & $137 \pm 3$ \\
\hline
\end{tabular}

Values are mean \pm SEM.

renin and displays species specificity for various isoforms of renin (30). The $\mathrm{IC}_{50}$ for aliskiren against mouse renin is 1 order of magnitude less effective than on the human enzyme ( $0.6 \mathrm{nM})$, but greater than its potency against the rat enzyme $(80 \mathrm{nM})$. The plasma aliskiren concentrations achieved with doses of drug in this study were all above the mouse $\mathrm{IC}_{50}$. Moreover, the functional inhibitory effect of aliskiren against mouse renin was demonstrated by reductions in plasma angiotensin peptide concentrations, with almost complete ablation of angiotensin peptides in plasma at higher drug doses.

Because renin conversion of angiotensinogen to AngI is the ratelimiting step in AngII formation, renin has long been considered the optimal target for RAS inhibition. Renin inhibition prevents formation of all angiotensin peptides. In contrast, ACE inhibitors do not influence non-ACE pathways such as chymase, while AT1 receptor inhibition increases circulating concentrations of angio- tensin peptides. In this study, we found that renin inhibition by aliskiren strikingly reduced atherosclerosis in mice. This contrasts with the effects of AT1a receptor deficiency, which were also profound, but not as efficacious as renin inhibition (6). Also, a survey of the literature for both ACE inhibition and AT1 receptor antagonists shows consistency with regard to reduced atherosclerotic lesion size, but not to the level attained with renin inhibition (7, $12,14,15,38,39)$. However, these differences need to be substantiated by comparing the different modes of RAS inhibition within a single study that uses multiple doses.

We have demonstrated previously that hypercholesterolemia was associated with increased RAS activity, as indicated by large increases in plasma concentrations of angiotensinogen and angiotensin peptides (6). In the present study, hypercholesterolemia was associated with increased systolic blood pressure. The role of angiotensin peptides in this elevation was demonstrated by renin inhibition reducing systolic blood pressure to a level observed in normolipidemic mice. Thus, there are several indications that renin inhibition was achieved with aliskiren to a level that affected physiological processes. Effective blockade of the RAS is associated with increased plasma renin concentrations, as demonstrated in the current study. This systemic increase results from release of renin in renal juxtaglomerular cells from AngII-induced negative feedback inhibition. The present results demonstrated that such increases in plasma renin concentration during aliskiren administration did not modulate the vasculoprotective effect of aliskiren. With increased systemic renin concentrations, there is the potential to interact with the recently cloned renin/prorenin receptor to activate fibrotic pathways (40). However, the relevance of high circulating concentrations of renin, and this receptor, to atherogenesis is unknown.
A

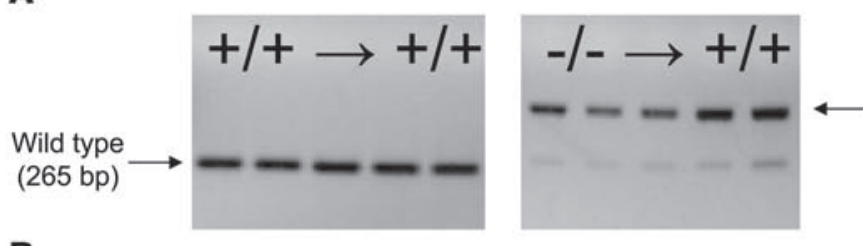

B

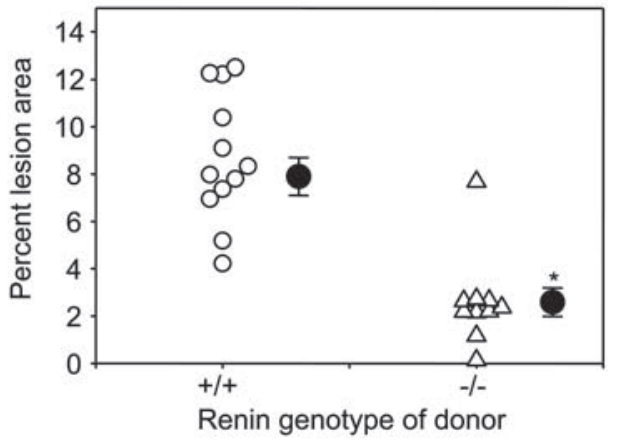

C Disrupted (386 bp)

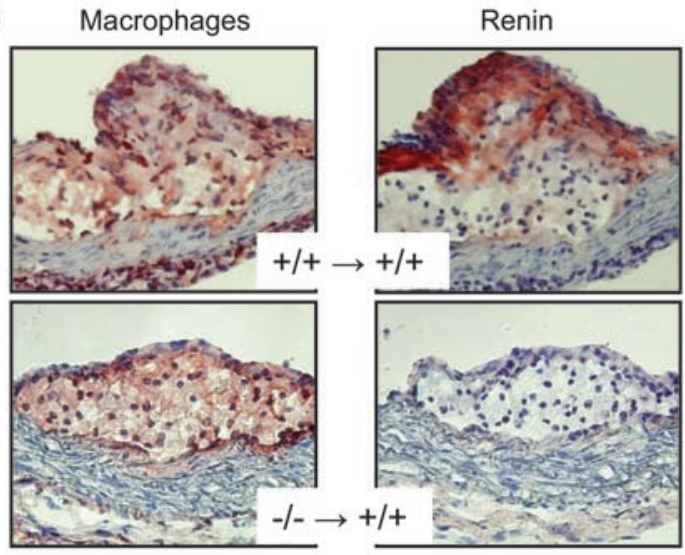

\section{Figure 5}

Renin deficiency in bone marrow-derived cells decreased atherosclerosis in Ldlr ${ }^{-1}$-recipient mice fed a high-fat diet. (A) PCR confirmed the presence of the disrupted renin gene in bone marrow cells from recipient mice. PCR on bone marrow-derived DNA yielded an amplicon of $265 \mathrm{bp}$ for the wild-type renin allele and $386 \mathrm{bp}$ for the disrupted allele. The lanes were run on the same gel but were noncontiguous. (B) Atherosclerotic lesion size was measured on aortic arch intimal surfaces. Individual $\mathrm{Ldll}^{-1-}$ recipients are represented by open symbols. Means of each group are represented by circles; error bars denote SEM. ${ }^{*} P<0.001$ renin $^{+/+}$donor $(n=12)$ versus renin ${ }^{-1-}$ donor $(n=10)$. (C) Renin deficiency in bone marrow-derived cells ablated renin expression in macrophages localized to atherosclerotic lesions in the aortic root. Immunostaining was performed in the atherosclerotic lesions of aortic root using rabbit anti-mouse macrophage antisera and a chicken anti-mouse renin IgY. Original magnification, $\times 200$. 


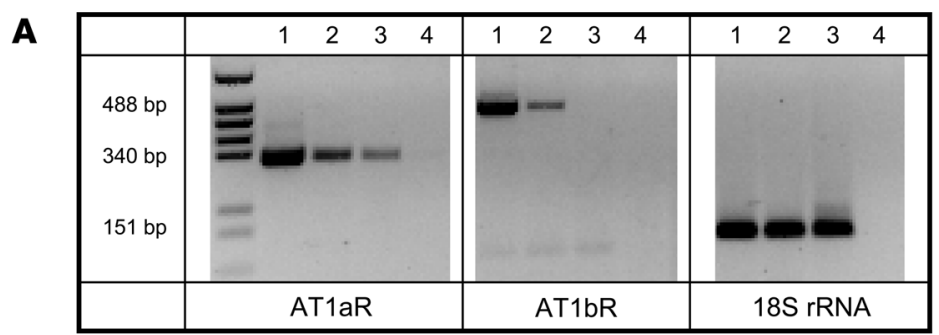

B

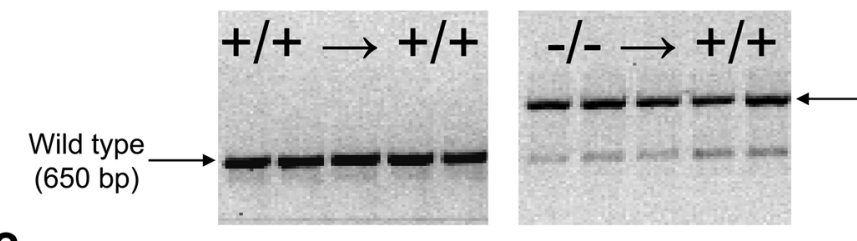

C

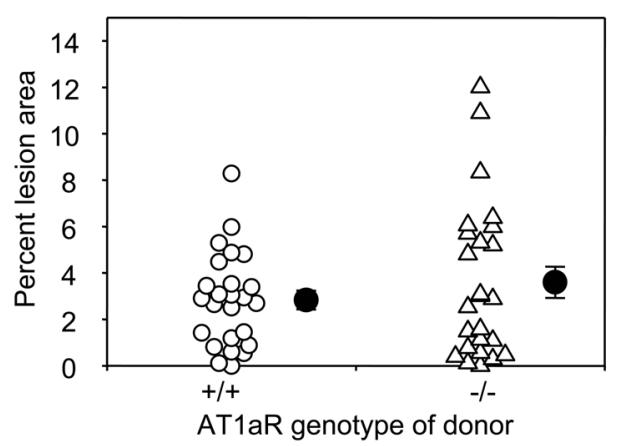

Reductions in atherosclerosis following aliskiren administration were profound in both vascular regions in which it was measured, with aortic root lesions having greater reductions than those in aortic arches. While higher doses of aliskiren reduced systolic blood pressure, reductions in atherosclerosis were achieved at doses of aliskiren that showed no persistent changes in blood pressure. In addition, we did not find any significant correlation between systolic blood pressure and atherosclerotic lesion size after we controlled for aliskiren dosage. Previously published studies have also demonstrated that AngII-augmented atherosclerosis is not a direct consequence of its ability to increase blood pressure. For example, while both AngII and norepinephrine increased blood pressure to the same extent in apoE $\mathrm{E}^{-/}$mice, only AngII accelerated atherosclerosis (10). Furthermore, the profound decreases in atherosclerotic lesion size during administration of AT1 receptor antagonists were not observed with either hydralazine or amlodipine when administered at doses resulting in equivalent reductions in systolic blood pressure $(7,41)$. Thus, while increased systolic blood pressure is frequently associated with atherosclerosis, the stimulus for the hypertension appears to be the major determinant of atherogenesis rather than pressure per se (42).

AngII is well known to augment specific oxidant pathways (43). This has been particularly well documented for the NADPH system in smooth muscle cells (43). AngII stimulation of this oxidant system has been consistently demonstrated to promote smooth muscle cell hypertrophy and hyperplasia $(43,44)$. However, NADPH oxidase has a poorly defined role in the development of atherosclerosis. Deficiency of 447 phox has previously been noted to decrease atherosclerotic lesion size in the aortic

\section{Figure 6}

AT1a receptor deficiency in bone marrow-derived cells did not alter atherosclerotic lesion size. (A) RT-PCR confirmed that macrophages expressed mRNA of AT1a receptors (AT1aR), but not of $A T 1 b$ receptors. Examples of positive controls (adrenal glands and aorta) and macrophages for AT1a receptors, AT1b receptors, and $18 \mathrm{~S}$ rRNA. Lane 1, adrenal gland; lane 2, aorta; lane 3, macrophages; lane 4 , non-RT negative control in adrenal glands. The lanes were run on the same gel but were noncontiguous. (B) PCR confirmed the presence of the disrupted AT1a receptor gene in mouse peritoneal macrophages from recipient mice. PCR on macrophagederived DNA yielded an amplicon of 650 bp for wild-type AT1a receptor and $1.1 \mathrm{~kb}$ for the disrupted allele. (C) Atherosclerotic lesion size was measured on aortic arch intimal surfaces. Individual symbols represent Ldlr-/- recipients. Means of each group are represented by circles; error bars denote SEM. $n=25$ (AT1a receptor ${ }^{+/+}$donor); 24 (AT1a receptor-1- donor). arch, but not the aortic root (45), while no effects were determined in another study (46). Furthermore, gp91phox deficiency had no effect on atherosclerotic lesion size (47). More emphasis regarding atherogenic mechanisms has been placed on extracellular oxidant processes that have led to the formation of protein adducts. Specific subtypes of lipoxygenases have been consistently linked to the atherogenic process (48). Previous studies have demonstrated that incubation of AngII with mouse peritoneal macrophages and J774 cells upregulated 12/15 lipoxygenase abundance and activity (33). However, we were unable to demonstrate any difference in $12 / 15$ lipoxygenase activity in macrophages from mice with profound renin inhibition. A more general index of oxidant stress has been the serum titers of autoantibodies to oxidatively modified proteins. Again, we were unable to detect any difference in the serum titers of autoantibodies to one of the most commonly described adducts, malondialdehyde. Thus, we were unable to define oxidant stress mechanisms that were associated with the profound reduction in atherosclerosis promoted by renin inhibition.

Deficiency of AT1a receptors has previously been shown to greatly decrease atherosclerotic lesion size in hyperlipidemic mice $(6,7)$. Although no direct comparisons have been performed, the relative extent of reductions in lesion size in the present study appeared larger during renin inhibition than that previously observed in mice with AT1a receptor deficiency or pharmacological blockade. Direct comparisons of the efficacy of renin inhibition, AT1 receptor blockade, and ACE inhibition on reduction in atherosclerotic lesion size are complicated by the definition of comparable inhibition for these 3 different mechanisms. However, the profound reductions in angiotensin peptides in this study do obviate the interpretation that the reductions in lesion size during AT1a receptor blockade were caused 


\section{Table 3}

Effects of AT1a receptor deficiency in bone marrow-derived cells in Ldlr ${ }^{-/-}$mice fed a fat-supplemented diet for 12 weeks

\begin{tabular}{lcc} 
& AT1a receptor ${ }^{+/+}$ & AT1a receptor ${ }^{-/-}$ \\
$n$ & 25 & 24 \\
Body wt $(\mathrm{g})$ & $28.0 \pm 0.9$ & $29.2 \pm 0.7$ \\
wbc count $\left(10^{3} / \mathrm{\mu l}\right)$ & $11.4 \pm 0.5$ & $10.5 \pm 0.8$ \\
Plasma cholesterol $(\mathrm{mg} / \mathrm{dl})$ & $621 \pm 43$ & $671 \pm 33$ \\
Plasma renin $(\mathrm{ng} / \mathrm{ml} / 30 \mathrm{~min})$ & $19.8 \pm 5.1$ & $27.4 \pm 4.8$ \\
\hline
\end{tabular}

Values are mean \pm SEM.

by enhanced stimulation of AT2 receptors $(39,49,50)$. Furthermore, these data demonstrate the benefit of inhibiting the synthesis of all angiotensin peptides on the development of atherosclerosis.

Renin deficiency in bone marrow-derived cells decreases atherosclerosis via the inhibition of monocyte adhesion to endothelial cells in the vascular wall. The major source of systemic concentrations of renin is the renal juxtaglomerular cells. While renin has been detected in several extrarenal tissues, it is unclear whether the levels of renin produced in extrarenal tissues is sufficient to have biological effects (20). In a previous study, we demonstrated that renin protein was detected by immunostaining in mouse atherosclerotic lesions (6). However, the renin detected in lesions may result from delivery of renin from other sources with retention by a receptor-based system $(40,51)$. In the current study, we demonstrated that cultured macrophages express a complete RAS, including renin mRNA. Furthermore, the creation of chimeric mice with renin deficiency in infiltrating macrophages clearly demonstrated that reductions in atherosclerosis could be achieved through deficiency of macrophage-derived renin. Importantly, reductions in atherosclerosis were seen in chimeric mice repopulated with renin-deficient bone marrow that exhibited no changes in plasma renin concentrations, demonstrating a pivotal role for macrophage-derived renin in atherosclerosis.

AngII has the potential to interact with many cell types to augment the atherogenic process. These include endothelial cells, smooth muscle cells, and macrophages. One potential mechanism by which renin within macrophages could be exerting its effect is the autocrine/paracrine effects of generated angiotensin peptides on macrophages. Our present results demonstrate that the absence of AT1a receptors in bone marrow-derived cells had no effect on lesion size in $\mathrm{Ldlr}^{-/-}$mice. This result is consistent with previous studies in our laboratory demonstrating that AT1a receptor deficiency in bone marrow-derived cells had minimal effects on AngII-induced atherosclerosis (11). These results indicate that macrophages are not the target cell type for AT1a receptors as a mediator of atherosclerosis.

The initiation and progression of atherosclerotic lesions is associated with monocyte adhesion to an intact endothelial surface $(52,53)$. Consistent with previous studies (54-57), we found that AngII augmented monocyte adhesion to endothelial cells. This was inhibited by incubation of endothelial cells with the AT1 receptor antagonist losartan. Monocyte adhesion to endothelial cells stimulated by macrophages from renin ${ }^{+/+}$mice was attenuated by macrophages from renin $^{-/-}$mice. These findings are consistent with macrophage-derived angiotensin peptides contributing to atherosclerosis via the effects on endothelial AT1 receptors. Our studies failed to demonstrate an association of augmented monocyte adhesion with increased endothelial VCAM-1 expression. While there has been a previous report of AngII increasing VCAM-1 expression in endothelial cells (58), in agreement with the present study, others have also failed to demonstrate increased VCAM-1 $(55-57,59)$. Thus, the in vitro data are consistent with AngII facilitating monocyte adhesion, although the regulator of this effect has not been identified. Because endothelial cells possess AT1a receptors and the function of this cell type regulates lesion development, future in vivo studies are needed to explore this axis using AT1a receptor-floxed mice.

In conclusion, renin inhibition profoundly decreased formation of atherosclerosis. Importantly, reductions in atherosclerosis were evident in $\mathrm{Ldlr}^{-/}$mice with deficiency of renin in bone marrowderived cells, invoking a prominent role for macrophage-derived renin in atherosclerosis.

\section{Methods}

\section{Mice and diet}

Ldlr $^{-/-}$(B6.129S7-Ldlr rm1Her, stock no. 002207), AT1a receptor ${ }^{-/-}$(B6.129P2Agtr1 $\mathrm{a}^{\mathrm{tm} 1 \mathrm{Unc}}$, stock no. 002682), and age-matched C57BL/6 male mice (stock no. 000664) were obtained from The Jackson Laboratory. Male renin $^{-/-}$mice on a C57BL/6 background (N9) were generated as previously described (60). LDLR and AT1a receptor genotypes were determined by PCR as described previously (6). Renin genotyping used the

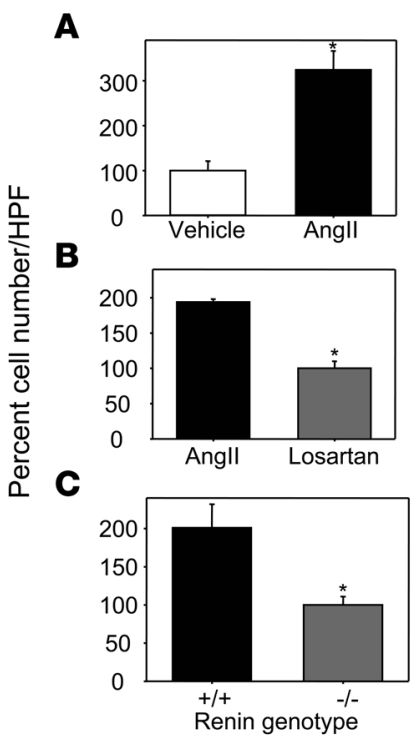

\section{Figure 7}

Renin deficiency in mouse macrophages markedly reduced monocyte adhesion to endothelial cells. (A) Angll resulted in increased THP-1 monocyte adhesion to endothelial cells. The adhesion assay was performed by coincubation of $10^{-7} \mathrm{M}$ Angll with HUVECs for 18 hours. Values (mean \pm SEM) represent cell number of each well relative to vehicle per HPF ( $n=4$ per group). ${ }^{*} P=0.009$ versus vehicle. (B) The AT1 receptor antagonist losartan inhibited Angll-induced THP-1 monocyte adhesion to endothelial cells. The adhesion assay was performed by coincubation of $10^{-7} \mathrm{M}$ Angll and $10^{-6} \mathrm{M}$ losartan. Losartan was added 2 hours prior to the addition of Angll to cultured HUVECs. Values (mean \pm SEM) represent cell number of each well relative to losartan per HPF ( $n=3$ per group). ${ }^{*} P<0.001$ versus Angll. (C) Renin deficiency resulted in decreased THP-1 monocyte adhesion to HUVECs. Cultured peritoneal macrophages from renin ${ }^{+/+}$or renin ${ }^{-/}$mice were coincubated with HUVECs for 24 hours, and an adhesion assay was then performed. Values (mean \pm SEM) represent cell number of each well relative to renin $^{-/-}$per HPF ( $n=4$ per group). ${ }^{*} P=0.03$ versus renin ${ }^{+/}$. 
following primers: 5'-ACTCTTGTTGCTCTGGAGTCCTT-3', 5'-AGTAGTAGAAGGGGGAGTTGTGG-3', 5'-GCTACCCGTGATATTGCTGAA-3', and $5^{\prime}$-CTTCCCAAAGCTGGCTTATTC- 3 '. The resultant wild-type and deficient allele bands were 265 and 386 bp, respectively. All mice were backcrossed 10 times into a C57BL/6 background. Littermates were selected for the studies reported in this manuscript.

All mice were maintained in a barrier facility and fed normal mouse laboratory diet. To induce hypercholesterolemia, mice were changed to a diet supplemented with saturated fat (milk fat $21 \% \mathrm{wt} / \mathrm{wt}$ ) and cholesterol (0.15\% wt/wt, diet no. TD88137; Harlan Teklad). All studies were performed with the approval of the University of Kentucky Institutional Animal Care and Use Committee.

\section{Aliskiren administration}

Model 2004 Alzet mini-osmotic pumps (Durect Corp.) were implanted into male Ldlr ${ }^{-/}$or C57BL/ 6 mice at the age of 6-8 weeks. Pumps were filled with either PBS $(n=15)$ or solutions of aliskiren dissolved in PBS $(2.5 \mathrm{mg} / \mathrm{kg} / \mathrm{d}$, $n=14 ; 25 \mathrm{mg} / \mathrm{kg} / \mathrm{d}, n=16 ; 50 \mathrm{mg} / \mathrm{kg} / \mathrm{d}, n=6)$ and replaced at 28-day intervals to continuously deliver solutions for a total of 12 weeks in $\operatorname{Ldlr} /-$ mice $(8,9)$. Aliskiren $(50 \mathrm{mg} / \mathrm{kg} / \mathrm{d})$ was infused for 4 weeks in C57BL $/ 6$ mice $(n=8)$.

\section{Irradiation and bone marrow repopulation}

This procedure was performed as described previously (11). Bone marrow was harvested from $\mathrm{renin}^{+/+}$or renin $/-$and AT1a receptor ${ }^{+/+}$or AT1a receptor ${ }^{-/-}$male mice $\left(6-8\right.$ weeks old) and injected $\left(1 \times 10^{7}\right.$ cells/mouse $)$ into age-matched male $\mathrm{Ldlr}^{-/}$recipient mice that had been irradiated. Four weeks after bone marrow repopulation, recipient mice were changed to a diet supplemented with fat for 12 weeks.

\section{Systolic blood pressure measurements}

Systolic blood pressure was measured using the Visitech tail cuff system (BP-2000 Visitech Systems) as described previously $(38,61)$. Systolic blood pressure measurements were performed 1 week before osmotic pump implantation and 2, 4, 8, and 12 weeks after implantation or 4, 8, and 12 weeks after bone marrow transplantation.

\section{Measurement of plasma components}

Lipid. Plasma cholesterol concentrations and lipoprotein cholesterol distributions were determined as described previously (9).

RAS. Concentrations of angiotensin peptides were determined by resolving plasma by HPLC and performing a radioimmunoassay on the fractions as described previously (62). Plasma renin and aldosterone concentrations were measured as described previously (6). For determination of the $\mathrm{IC}_{50}$ for aliskiren, plasma ( $8 \mu \mathrm{l})$ from 3-month fat-fed Ldlr ${ }^{-1}$ mice $(n=3)$ was incubated with an excess of rat angiotensinogen in the absence and presence of aliskiren $(0.01-100 \mathrm{nM})$ for 30 minutes at $37^{\circ} \mathrm{C}$. AngI was measured by radioimmunoassay (Diagnostic Systems Laboratories).

Aliskiren concentration. Plasma concentrations of aliskiren were measured by liquid chromatography/mass spectrometry as described previously (63).

Oxidation autoantibody titers. Serum autoantibodies to MDA-LDL were measured by ELISA as described previously (64).

\section{Atherosclerosis quantification}

Atherosclerosis was quantified both on the aortic intima of the arch and in the root as described previously $(65,66)$.

\section{Cholesterol content in macrophages}

Resident mouse peritoneal macrophages were obtained from male renin ${ }^{+/+}$ or renin ${ }^{-/-}$mice (6-8 weeks old) as described previously (67). Cells were incubated with DMEM supplemented with $10 \% \mathrm{vol} / \mathrm{vol}$ FBS and antibiot- ics (penicillin G, $100 \mathrm{IU} / \mathrm{ml}$, and streptomycin, $100 \mu \mathrm{g} / \mathrm{ml}$ ) overnight. Cells were washed with serum-free DMEM to remove nonadherent cells, and monolayers were incubated in serum-free DMEM in the presence of acetylated LDL $(20 \mu \mathrm{g} / \mathrm{ml}$; Intracel) for 24 hours. Macrophages were extracted with chloroform/methanol at a 2:1 ratio with $5 \alpha$-cholestane added as an internal standard. Lipid extracts were dissolved in methylene chloride. Unesterified cholesterol was quantified by GC-MS using a CP-3800 gas chromatograph and a Saturn 2200 mass spectrometry (Varian) equipped with a DB-5 MS column (J \& W Scientific Inc.). Saponification was performed to determine total cholesterol. Cholesterol measurements were normalized to cellular protein.

\section{mRNA abundance of RAS components}

RNA was harvested from mouse tissues and peritoneal macrophages using the SV Total RNA Isolation System (Promega). RT-PCR or real-time PCR was performed as described previously $(6,36)$. mRNA abundances were calculated with normalization to either $18 \mathrm{~S}$ rRNA or $\beta$-actin. Nontemplate and non-RT reactions were used as negative controls.

\section{Immunostaining}

Macrophages were detected using rat anti-mouse CD68 (FA-11, catalog no. MCA 1957; Serotec) or rabbit anti-mouse macrophage serum (catalog no. AIA31240; Accurate Chemical Company) as described previously (6). Smooth muscle cells and endothelial cells were detected using rabbit anti$\alpha$-SMA (catalog no. ab5694; Abcam) and biotin-conjugated rat anti-mouse CD31 monoclonal antibody (PECAM-1, catalog no. 553371; BD Biosciences - Pharmingen), respectively. Immunostaining was performed on frozen sections, with appropriate negative controls, as described previously $(64,68)$.

\section{Adbesion assay}

HUVECs were isolated from human umbilical cords obtained from the University of Kentucky Labor and Delivery unit and cultured in M199 media supplemented with $20 \%$ FBS as described previously (69). Passages 1-5 were grown to confluence in cell culture inserts coated with human fibronectin (catalog no. 354492; BD). Plates were washed with PBS, and monolayers were incubated in M199 media with FBS (1\% vol/vol) overnight. Cells were incubated for 24 hours with AngII $\left(10^{-7} \mathrm{M}\right)$, losartan $\left(10^{-6} \mathrm{M}\right)$, or peritoneal macrophages from renin ${ }^{+/+}$or renin ${ }^{-/-}$mice placed in the lower chamber. Adhesion assays were performed as described by Huber et al. (70). Briefly, THP-1 cells were stimulated by TNF- $\alpha(10 \mathrm{ng} / \mathrm{ml})$ and then labeled with calcein AM (catalog no. C-3099; Invitrogen). Labeled cells $\left(5 \times 10^{4} /\right.$ well $)$ were added to the upper chamber of each well. After incubating for $30 \mathrm{~min}$ utes at $37^{\circ} \mathrm{C}$, unbound cells were washed off, and bound THP- 1 cells were fixed with glutaraldehyde ( $1 \% \mathrm{wt} / \mathrm{vol})$. Bound monocytes were counted by an inverted phase-contrast microscope. A minimum of 4 high-power fields (HPFs) of each well were counted by at least 2 observers that were blinded to the experimental design. The percent adhesion was calculated as the mean cell number of each well relative to the mean cell number of vehicle.

\section{Western blotting analyses}

Western blotting analyses of angiotensinogen in plasma and cultured macrophage medium, and 12/15 lipoxygenase in macrophages were performed as described previously $(6,71)$. Western blotting of VCAM- 1 in cultured HUVECs was performed using mouse anti-human CD106 (catalog no. 555645; BD Biosciences - Pharmingen).

\section{Statistics}

To compare 2 groups on a continuous response variable, we used a 2-sample $t$ test. To compare more than 2 groups on a continuous response variable, we used 1-way ANOVA; however, if the assumptions for the ANOVA 
were not satisfied, we either performed the ANOVA on log-transformed values or used the Kruskal-Wallis procedure. For repeated-measures data, we fitted an appropriate linear mixed model. Relationships between systolic blood pressure and atherosclerotic lesion size were analyzed using Pearson correlations and linear regression models. A $P$ value less than 0.05 was considered statistically significant. Data are presented as mean \pm SEM. SAS version 9.1 (SAS Institute) was used to carry out data analyses.

\section{Acknowledgments}

These studies were supported by Novartis Institute for Biomedical Research, the National Institutes of Health (grant HL62846), and an American Heart Association Ohio Valley Postdoctoral Fellowship to H. Lu. We acknowledge the skilled technical assistance of Deborah Howatt, Jessica Moorleghen, and Victoria English. The authors also thank Weiyi Zheng (Novartis) for performing mea- surements of plasma aliskiren concentrations, John May (University of Kentucky) for performing GC-MS cholesterol assays, and Thomas E. Curry (University of Kentucky) for providing human umbilical cords for HUVECs.

Received for publication June 12, 2007, and accepted in revised form January 2, 2008.

Address correspondence to: Alan Daugherty or Lisa A. Cassis, Wethington Building, Room 521, 900 S. Limestone Street, University of Kentucky, Lexington, Kentucky 40536-0200, USA. Phone: (859) 323-4933 ext. 81389; Fax: (859) 257-3646; E-mail: Alan.Daugherty@uky.edu (A. Daugherty). Phone: (859) 3234933 ext. 81400; Fax: (859) 257-3646; E-mail: Lcassis@uky.edu (L.A. Cassis).
1. Ferrario, C.M. 2002. Angiotensin I, angiotensin II and their biologically active peptides. J. Hypertens. 20:805-807.

2. Cesari, M., Rossi, G.P., and Pessina, A.C. 2002. Biological properties of the angiotensin peptides other than angiotensin II: implications for hypertension and cardiovascular diseases. J. Hypertens. 20:793-799.

3. Carey, R.M., and Siragy, H.M. 2003. Newly recognized components of the renin-angiotensin system: potential roles in cardiovascular and renal regulation. Endocr. Rev. 24:261-271.

4. Santos, R.A., et al. 2003. Angiotensin-(1-7) is an endogenous ligand for the $G$ protein-coupled receptor Mas. Proc. Natl. Acad. Sci. U. S. A. 100:8258-8263.

5. Moeller, I., Chai, S.Y., Smith, I., Lew, R., and Mendelsohn, F.A. 1998. Haemorphin peptides may be endogenous ligands for brain angiotensin AT4 receptors. Clin. Exp. Pharmacol. Physiol. Suppl. 25:S68-S71.

6. Daugherty, A., Rateri, D.L., Lu, H., Inagami, T., and Cassis, L.A. 2004. Hypercholesterolemia stimulates angiotensin peptide synthesis and contributes to atherosclerosis through the AT1A receptor. Circulation. 110:3849-3857.

7. Wassmann, S., et al. 2004. Inhibition of dietinduced atherosclerosis and endothelial dysfunction in apolipoprotein E/Angiotensin II type $1 \mathrm{~A}$ receptor double-knockout mice. Circulation. 110:3062-3067.

8. Daugherty, A., and Cassis, L. 1999. Chronic angiotensin II infusion promotes atherogenesis in low density lipoprotein receptor-/- mice. Ann. N. Y. Acad. Sci. 892:108-118.

9. Daugherty, A., Manning, M.W., and Cassis, L.A. 2000. Angiotensin II promotes atherosclerotic lesions and aneurysms in apolipoprotein E-deficient mice. J. Clin. Invest. 105:1605-1612.

10. Weiss, D., Kools, J.J., and Taylor, W.R. 2001. Angiotensin II-induced hypertension accelerates the development of atherosclerosis in ApoE-deficient mice. Circulation. 103:448-454.

11. Cassis, L.A., Rateri, D.L., Lu, H., and Daugherty, A. 2007. Bone marrow transplantation reveals that recipient AT1a receptors are required to initiate angiotensin II-induced atherosclerosis and aneurysms. Arterioscler. Thromb. Vasc. Biol. 27:380-386.

12. Candido, R., et al. 2002. Prevention of accelerated atherosclerosis by angiotensin-converting enzyme inhibition in diabetic apolipoprotein E-deficient mice. Circulation. 106:246-253.

13. Hayek, T., et al. 2002. Ramipril administration to atherosclerotic mice reduces oxidized low-density lipoprotein uptake by their macrophages and blocks the progression of atherosclerosis. Atherosclerosis. 161:65-74.

14. da Cunha, V., et al. 2005. Enalapril attenuates angiotensin II-induced atherosclerosis and vascular inflammation. Atherosclerosis. 178:9-17.
15. Candido, R., et al. 2004. Irbesartan but not amlodipine suppresses diabetes-associated atherosclerosis. Circulation. 109:1536-1542.

16. Cassis, L.A., Lynch, K.R., and Peach, M.J. 1988. Localization of angiotensinogen messenger RNA in rat aorta. Circ. Res. 62:1259-1262.

17. Dostal, D.E., and Baker, K.M. 1999. The cardiac renin-angiotensin system: conceptual, or a regulator of cardiac function? Circ. Res. 85:643-650.

18. De Mello, W.C., and Danser, A.H. 2000. Angiotensin II and the heart: on the intracrine renin-angiotensin system. Hypertension. 35:1183-1188.

19. Bataller, R., et al. 2003. Activated human hepatic stellate cells express the renin-angiotensin system and synthesize angiotensin II. Gastroenterology. 125:117-125.

20. Danser, A.H. 2003. Local renin-angiotensin systems: the unanswered questions. Int. J. Biochem. Cell Biol. 35:759-778.

21. Diet, F., et al. 1996. Increased accumulation of tissue ACE in human atherosclerotic coronary artery disease. Circulation. 94:2756-2767.

22. Ohishi, M., et al. 1997. Enhanced expression of angiotensin-converting enzyme is associated with progression of coronary atherosclerosis in humans. J. Hypertens. 15:1295-1302.

23. Potter, D.D., Sobey, C.G., Tompkins, P.K., Rossen, J.D., and Heistad, D.D. 1998. Evidence that macrophages in atherosclerotic lesions contain angiotensin II. Circulation. 98:800-807.

24. Gomez, R.A., et al. 1993. Leukocytes synthesize angiotensinogen. Hypertension. 21:470-475.

25. Iwai, N., Inagami, T., Ohmichi, N., and Kinoshita, M. 1996. Renin is expressed in rat macrophage/ monocyte cells. Hypertension. 27:399-403.

26. Okamura, A., et al. 1999. Upregulation of renin-angiotensin system during differentiation of monocytes to macrophages. J. Hypertens. 17:537-545.

27. Mehta, P.K., and Griendling, K.K. 2007. Angiotensin II cell signaling: physiological and pathological effects in the cardiovascular system. Am. J. Physiol. Cell Physiol. 292:C82-C97.

28. Savoia, C., and Schiffrin, E.L. 2006. Inhibition of the renin angiotensin system: implications for the endothelium. Curr. Diab. Rep. 6:274-278.

29. Nussberger, J., Wuerzner, G., Jensen, C., and Brunner, H.R. 2002. Angiotensin II suppression in humans by the orally active renin inhibitor Aliskiren (SPP100): comparison with enalapril. Hypertension. 39:E1-E8.

30. Wood, J.M., et al. 2003. Structure-based design of aliskiren, a novel orally effective renin inhibitor. Biochem. Biophys. Res. Commun. 308:698-705.

31. Azizi, M., Webb, R., Nussberger, J., and Hollenberg, N.K. 2006. Renin inhibition with aliskiren: where are we now, and where are we going? J. Hypertens. 24:243-256.

32. Pickering, T.G., et al. 2005. Recommendations for blood pressure measurement in humans and experimental animals: part 1: blood pressure measurement in humans: a statement for professionals from the Subcommittee of Professional and Public Education of the American Heart Association Council on High Blood Pressure Research. Circulation. 111:697-716.

33. Scheidegger, K.J., Butler, S., and Witztum, J.L. 1997. Angiotensin II increases macrophage-mediated modification of low density lipoprotein via a lipoxygenase-dependent pathway. J. Biol. Chem. 272:21609-21615.

34. George, J., et al. 2001. 12/15-lipoxygenase gene disruption attenuates atherogenesis in LDL receptordeficient mice. Circulation. 104:1646-1650.

35. Palinski, W., et al. 1994. ApoE-deficient mice are a model of lipoprotein oxidation in atherogenesis - Demonstration of oxidation-specific epitopes in lesions and high titers of autoantibodies to malondialdehyde-lysine in serum. Arterioscler. Thromb. 14:605-616.

36. Lu, H., Boustany-Kari, C.M., Daugherty, A., and Cassis, L.A. 2007. Angiotensin II increases adipose angiotensinogen expression. Am.J. Physiol. Endocrinol. Metab. 292:E1280-E1287.

37. Bentzon, J.F., et al. 2006. Smooth muscle cells in atherosclerosis originate from the local vessel wall and not circulating progenitor cells in ApoE knockout mice. Arterioscler. Thromb. Vasc. Biol. 26:2696-2702.

38. Daugherty, A., Manning, M.W., and Cassis, L.A. 2001. Antagonism of AT2 receptors augments Angiotensin II-induced abdominal aortic aneurysms and atherosclerosis. Br. J. Pharmacol. 134:865-870.

39. Strawn, W.B., Chappell, M.C., Dean, R.H., Kivlighn, S., and Ferrario, C.M. 2000. Inhibition of early atherogenesis by losartan in monkeys with diet-induced hypercholesterolemia. Circulation. 101:1586-1593

40. Nguyen, G., et al. 2002. Pivotal role of the renin/ prorenin receptor in angiotensin II production and cellular responses to renin. J. Clin. Invest. 109:1417-1427.

41. Doran, D.E., Weiss, D., Zhang, Y., Griendling, K.K., and Taylor, W.R. 2007. Differential effects of AT(1) receptor and $\mathrm{Ca}(2+)$ channel blockade on atherosclerosis, inflammatory gene expression, and production of reactive oxygen species. Atherosclerosis. 195:39-47.

42. Lu, H., Cassis, L.A., and Daugherty, A. 2007. Atherosclerosis and arterial blood pressure in mice. Curr. Drug Targets. 8:1181-1189.

43. Griendling, K.K., Minieri, C.A., Ollerenshaw, J.D., and Alexander, R.W. 1994. Angiotensin II stimulates NADH and NADPH oxidase activity in cultured vascular smooth muscle cells. Circ. Res. 74:1141-1418 
44. Touyz, R.M. 2005. Intracellular mechanisms involved in vascular remodelling of resistance arteries in hypertension: role of angiotensin II. Exp. Physiol. 90:449-455.

45. Barry Lane, P.A., et al. 2001. p47phox is required for atherosclerotic lesion progression in $\mathrm{ApoE}(-/-)$ mice. J. Clin. Invest. 108:1513-1522.

46. Thomas, M., et al. 2006. Deletion of p47phox attenuates angiotensin II-induced abdominal aortic aneurysm formation in apolipoprotein E-deficient mice. Circulation. 114:404-413.

47. Kirk, E.A., et al. 2000. Impaired superoxide production due to a deficiency in phagocyte NADPH oxidase fails to inhibit atherosclerosis in mice. Arterioscler. Thromb. Vasc. Biol. 20:1529-1535.

48. Cornicelli, J.A., and Trivedi, B.K. 1999. 15-lipoxygenase and its inhibition: A novel therapeutic target for vascular disease. Curr. Pharm. Des. 5:11-20.

49. Iwai, M., et al. 2005. Deletion of angiotensin II type 2 receptor exaggerated atherosclerosis in apolipoprotein E-null mice. Circulation. 112:1636-1643.

50. Sales, V.L., et al. 2005. Angiotensin type 2 receptor is expressed in murine atherosclerotic lesions and modulates lesion evolution. Circulation. 112:3328-3336.

51. Nguyen, G. 2007. The (pro)renin receptor: pathophysiological roles in cardiovascular and renal pathology. Curr. Opin. Nephrol. Hypertens. 16:129-133.

52. Lusis, A.J. 2000. Atherosclerosis. Nature. 407:233-241.

53. Glass, C.K., Witztum, J.L. 2001. Atherosclerosis: The road ahead. Cell. 104:503-516.

54. Hahn, A.W., Jonas, U., Buhler, F.R., and Resink, T.J. 1994. Activation of human peripheral monocytes by angiotensin II. FEBS Lett. 347:178-180.

55. Kim, J.A., Berliner, J.A., and Nadler, J.L. 1996. Angiotensin II increases monocyte binding to endothelial cells. Biochem. Biophys. Res. Commun. 226:862-868.

56. Grafe, M., et al. 1997. Angiotensin II-induced leukocyte adhesion on human coronary endothelial cells is mediated by E-selectin. Circ. Res. 81:804-811.

57. Soehnlein, O., et al. 2005. ACE inhibition lowers angiotensin-II-induced monocyte adhesion to HUVEC by reduction of $\mathrm{p} 65$ translocation and AT 1 expression. J. Vasc. Res. 42:399-407.

58. Pueyo, M.E., et al. 2000. Angiotensin II stimulates endothelial vascular cell adhesion molecule-1 via nuclear factor-kappa B activation induced by intracellular oxidative stress. Arterioscler. Thromb. Vasc. Biol. 20:645-651.

59. Costanzo, A., et al. 2003. Endothelial activation by angiotensin II through NFkappaB and p38 pathways: Involvement of NFkappaB-inducible kinase (NIK), free oxygen radicals, and selective inhibition by aspirin. J. Cell. Physiol. 195:402-410.

60. Yanai, K., et al. 2000. Renin-dependent cardiovascular functions and renin-independent blood- brain barrier functions revealed by renin-deficient mice. J. Biol. Chem. 275:5-8.

61. Cassis, L.A., Helton, M.J., Howatt, D.A., King, V.L., and Daugherty, A. 2005. Aldosterone does not mediate angiotensin II-induced atherosclerosis and abdominal aortic aneurysms. Br. J. Pharmacol. 144:443-448.

62. Cassis, L.A., Huang, J., Gong, M.C., and Daugherty, A. 2004. Role of metabolism and receptor responsiveness in the attenuated responses to Angiotensin II in mice compared to rats. Regul.
Pept. 117:107-116.

63. Dieterle, W., Corynen, S., and Mann, J. 2004. Effect of the oral renin inhibitor aliskiren on the pharmacokinetics and pharmacodynamics of a single dose of warfarin in healthy subjects. Br. J. Clin. Pharmacol. 58:433-436.

64. Daugherty, A., et al. 1997. The effects of total lymphocyte deficiency on the extent of atherosclerosis in apolipoprotein $\mathrm{E}-/-$ mice. J. Clin. Invest. 100:1575-1580.

65. Daugherty, A., and Whitman, S.C. 2003. Quantification of atherosclerosis in mice. Methods Mol. Biol. 209:293-309.

66. Daugherty, A., and Rateri, D.L. 2005. Development of experimental designs for atherosclerosis studies in mice. Methods. 36:129-138.

67. Daugherty, A., Whitman, S.C., Block, A.E., and Rateri, D.L. 2000. Polymorphism of class A scavenger receptors in C57BL/6 mice. J. Lipid Res. 41:1568-1577.

68. Lu, H., Rateri, D.L., and Daugherty, A. 2007. Immunostaining in mouse atherosclerosis. Methods Mol. Biol. 139:77-94.

69. Toborek, M., Lee, Y.W., Kaiser, S., and Hennig, B. 2002. Measurement of inflammatory properties of fatty acids in human endothelial cells. Methods Enzymol. 352:198-219.

70. Huber, J., et al. 2006. Specific monocyte adhesion to endothelial cells induced by oxidized phospholipids involves activation of cPLA2 and lipoxygenase. J. Lipid Res. 47:1054-1062.

71. Cornicelli, J.A., Butteiger, D., Rateri, D.L., Welch, K. and Daugherty, A. 2000. Interleukin-4 augments acetylated LDL induced cholesterol esterification in macrophages. J. Lipid Res. 41:376-383. 